\title{
Ginsenoside Rg1 attenuates the inflammation and oxidative stress induced by diabetic nephropathy through regulating the PI3K/ AKT/FOXO3 pathway
}

\author{
Hui Liu ${ }^{1}$, Wenli Chen ${ }^{1}$, Ping Lu², Yifei Ma ${ }^{2}$, Xinjun Liang ${ }^{2}$, Yanyan Liu ${ }^{3}$ \\ ${ }^{1}$ Department of Nephrology, The Central Hospital of Wuhan, Tongji Medical College, Huazhong University of Science and Technology, Wuhan, \\ China; ${ }^{2}$ Department of Medical Oncology, Hubei Cancer Hospital, Tongji Medical College, Huazhong University of Science, Wuhan, China; \\ ${ }^{3}$ Department of Nephrology, Division of Internal Medicine, Tongji Hospital, Tongji Medical College, Huazhong University of Science and \\ Technology, Wuhan, China \\ Contributions: (I) Conception and design: H Liu, P Lu; (II) Administrative support: Y Ma, X Liang, Y Liu; (III) Provision of study materials or \\ patients: W Chen, Y Ma; (IV) Collection and assembly of data: H Liu, W Chen; (V) Data analysis and interpretation: H Liu, W Chen; (VI) \\ Manuscript writing: All authors; (VII) Final approval of manuscript: All authors. \\ Correspondence to: Xinjun Liang. Department of Medical Oncology, Hubei Cancer Hospital, Tongji Medical College, Huazhong University of \\ Science, Wuhan, China. Email: liangxj19@163.com; Yanyan Liu. Department of Nephrology, Division of Internal Medicine, Tongji Hospital, Tongji \\ Medical College, Huazhong University of Science and Technology, Wuhan, China. Email: tjliuyy@163.com.
}

Background: Diabetic nephropathy (DN) is one of the most common microvascular complications in diabetes mellitus. Ginsenoside $\operatorname{Rg} 1(\mathrm{Rg} 1)$ is an important active ingredient extracted from Panax ginseng. This study aimed to investigate the role and molecular mechanism of Rg1 in DN model.

Methods: The mesangial cell line HBZY-1 was induced by high glucose (HG; $30 \mathrm{mM}$ D-glucose). HGinduced HBZY-1 cells were treated with $\operatorname{Rg} 1(2.5,5,10 \mu \mathrm{mol} / \mathrm{L})$. Cell viability was measured by the MTT assay. Apoptosis was detected by flow cytometry. Related proteins were measured by western blot. Reactive oxygen species (ROS) production was measured by dichlorodihydrofluorescein diacetate (DCFHDA). Inflammatory factors and molecules associated with oxidative stress were detected by enzyme-linked immunoassay (ELISA). DN rats model were treated with $50 \mathrm{mg} / \mathrm{kg} / \mathrm{d} \mathrm{Rg} 1$ for 8 weeks, the histopathological changes and the expression of relevant markers were analyzed.

Results: We found that $\operatorname{Rg} 1$ treatment markedly elevated the survival rates of HG-induced HBZY-1 cells and reduced apoptosis induced by HG. Rg1 treatment attenuated the HG-induced inflammatory response by decreasing the high levels of TNF- $\alpha$, IL-1 $\beta$, and IL-6. Furthermore, Rg1 treatment alleviated HGinduced oxidative stress by decreasing ROS generation, malondialdehyde (MDA), and lactate dehydrogenase $(\mathrm{LDH})$ accumulation and increasing the activities of superoxide dismutase (SOD) and glutathione peroxidase (GSH-Px). After Rg1 (50 mg/kg/d) treatment, the severe glomerular thylakoid hyperplasia, glomerular atrophy, tubule dermal cell exfoliation, basement membrane exposure, interstitial edema and inflammatory cell cytoplasmic infiltration were alleviated in DN rats. DN rat model treated with $\mathrm{Rg} 1(50 \mathrm{mg} / \mathrm{kg} / \mathrm{d})$ showed good anti-inflammatory and antioxidant activities. Rg1 treatment also increased the levels of the phosphorylation of PI3K (p-PI3K) and AKT (p-AKT) and promoted the transfer of FOXO3 from the nucleus to the cytoplasm in vitro and in vivo.

Conclusions: $\mathrm{Rg} 1$ exhibited protective effects on DN-induced inflammatory responses and oxidative stress via regulating the PI3K/AKT/FOXO3 pathway in in vitro and in vivo. The results suggest that $\operatorname{Rg} 1$ may be a potential therapeutic agent for DN treatment.

Keywords: Ginsenoside $\operatorname{Rg} 1$ ( $\mathrm{Rg} 1$ ); high glucose (HG); oxidative stress; PI3K/AKT/FOXO3; diabetic nephropathy (DN)

Submitted Nov 08, 2021. Accepted for publication Dec 17, 2021.

doi: $10.21037 / \mathrm{atm}-21-6234$

View this article at: https://dx.doi.org/10.21037/atm-21-6234 


\section{Introduction}

Diabetic nephropathy (DN) is a common microvascular complication of diabetes mellitus worldwide, which often increases the risk of chronic renal failure (1). Glomerular mesangial cells (GMCs) are a major functional cell type which plays crucial roles in sustaining the integrity of the glomerular microvascular bed, preserving mesangial matrix homeostasis, and regulating glomerular percolation (2). Research indicated that mesangial cell death was an important cause of diabetes-mediated renal tissue destruction (3). Once GMCs are destroyed, glomerular sclerosis and renal tubular interstitial fibrosis will occur, ultimately leading to DN. Therefore, inhibition of GMC apoptosis plays an important role in the prevention and treatment of DN.

Studies have shown that oxidative stress plays vital roles in DN (4). Excess oxidative stress will result in glomerulosclerosis and renal fibrosis, eventually leading to DN (5). High glucose-induced (HG-induced) oxidative stress contributed to endothelial dysfunction, vacuolation of renal tubular epithelial cells, tubular fibrosis, and interstitial inflammation (6). Therefore, oxidative stress plays an important role in kidney injury $(7,8)$.

Ginsenoside $\operatorname{Rg} 1(\operatorname{Rg} 1)$ is one of the primary bioactive ingredients in Panax notoginseng saponins. Numerous studies have indicated that $\mathrm{Rg} 1$ plays significant roles in health benefits such as anticancer (9), neuroprotective (10), antisenescence (11), anti-inflammation (12), and antioxidative (13) effects. Also, extensive research has demonstrated that $\operatorname{Rg} 1$ is associated with various diseases, including cardiovascular disease (14), Alzheimer's disease (15), spinal cord injury (16), and liver injury $(17,18)$. Xue et al. and Yu et al. demonstrated that $\operatorname{Rg} 1$ ameliorated streptozotocin-induced oxidative stress and myocardial apoptosis, and suppressed HG-induced mesenchymal activation and fibrosis $(19,20)$. However, to our knowledge, the detailed mechanisms of $\mathrm{Rg} 1$ on HG-induced oxidative stress in GMCs have not been described.

Forkhead box O (FOXO) is an O type superfamily of forkhead transcription factors distributed in the nucleus which are involved in various cell processes (21-24). FOXO3 transcription factors, which are downstream effectors of the PI3K/AKT signal pathway $(25,26)$, play a crucial role in cell cycle arrest and cell survival (27). The activated PI3K/AKT pathway was shown to promote FOXO3 phosphorylation, and the phosphorylated FOXO3 went into the cytoplasm, inhibited apoptosis, and eventually promoted cell proliferation and survival (28). Additionally,
FOXO3 correlated with some important anti-apoptotic proteins which act against oxidative stress in cellular protection (29-31).

In the present study, we investigated for the first time the roles and the underlying mechanism of $\mathrm{Rg} 1$ on $\mathrm{DN}$ induced inflammation and oxidative stress. Our findings indicate that $\operatorname{Rg} 1$ may act as an attractive therapeutic agent for intervention against renal failure.

We present the following article in accordance with the MDAR reporting checklist (available at https://dx.doi. org/10.21037/atm-21-6234).

\section{Methods}

\section{Cell culture and treatment}

The rat GMC line (HBZY-1 cells) was cultured in Dulbecco's modified Eagle's medium (DMEM). Then, the cells were cultured with $30 \mathrm{mmol} / \mathrm{L}$ glucose $(\mathrm{HG})$ for 48 h. Rg1 (CAS: 22427-39-0, $\geq 90 \%$ HPLC) was purchased from Sigma-Aldrich (USA), which chemical structure was shown in Figure $1 A$. There were 5 groups in this study: control group (HBZY-1 cells with no treatment); HG group (HBZY-1 cells were induced by $30 \mathrm{mmol} / \mathrm{L}$ glucose); HG + Rg1 (2.5, 5, $10 \mu \mathrm{mol} / \mathrm{L})$ group, where HBZY-1 cells induced by HG were treated with $2.5,5$, and $10 \mu \mathrm{mol} / \mathrm{L} \mathrm{Rg} 1$. Cells were cultured at $37^{\circ} \mathrm{C}$ for $48 \mathrm{~h}$.

\section{Cell viability}

The viability of HBZY-1 cells was measured by the MTT assay (Solarbio, China). The cells $\left(5 \times 10^{3}\right.$ cells per well) were seeded on a 96 -well plate. After $24 \mathrm{~h}$ of culture, cells in the HG group were treated with HG for $48 \mathrm{~h}$. HGinduced cells in the $\mathrm{Rg} 1$ group were treated with $\operatorname{Rg} 1$ (2.5, $5,10 \mu \mathrm{mol} / \mathrm{L}$ ) and cultured for $48 \mathrm{~h}$. The control cells were cultured in normal medium. After MTT treatment, the OD value was detected at $490 \mathrm{~nm}$ with a microplate reader (Multiskan Sky, Thermo Fisher, USA).

\section{Flow cytometry}

The cells were digested with trypsin (Solarbio, China) and fixed with $70 \%$ ethanol at $4{ }^{\circ} \mathrm{C}$ overnight. Then, $10 \mathrm{mg} / \mathrm{mL}$ RnaseA (Solarbio, China) and propidium iodide (PI) (Solarbio, China) were added and stained overnight at $4{ }^{\circ} \mathrm{C}$. Following the instructions of the Annexin V-FITC Apoptosis 

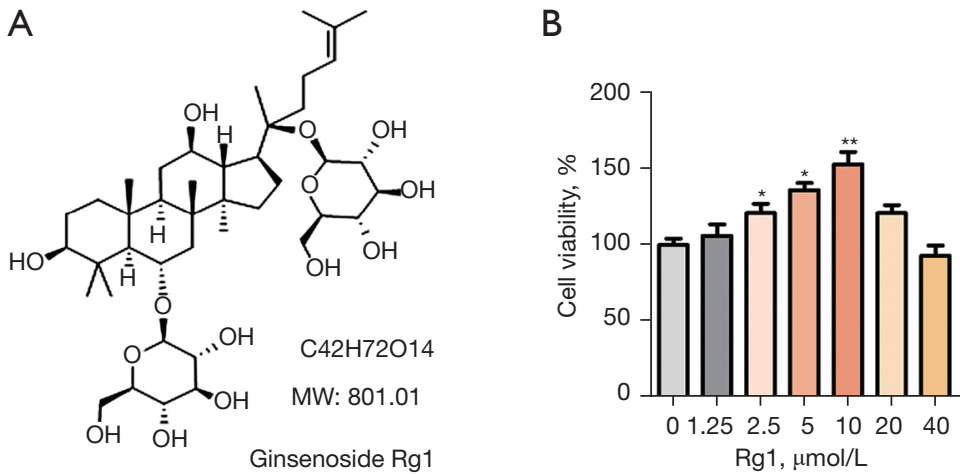

C

Figure $1 \mathrm{Rg} 1$ elevated the survival rate of HG-induced HBZY-1 cells. (A) The chemical structure of Rg1. (B) HBZY-1 cells were treated with $0,1.25,2.5,5,10,20$, or $40 \mu \mathrm{mol} / \mathrm{L} \mathrm{Rg1}$, and cell viability was evaluated by the MTT assay. $\left({ }^{*} \mathrm{P}<0.05\right.$, ${ }^{* *} \mathrm{P}<0.01$ versus 0$)$. (C) $\mathrm{HBZY}$ 1 cells were induced by HG (30 mmol/L). HBZY-1 cells were divided into 5 groups: control group (HBZY-1 cells without any treatment); HG group (HBZY-1 cells were induced by $30 \mathrm{mmol} / \mathrm{L}$ glucose); HG + Rg1 (2.5, 5, 10 umol/L) group, where HG-induced HBZY-1 cells were treated with $2.5,5$, and $10 \mu \mathrm{mol} / \mathrm{L} \mathrm{Rg} 1$ at $37^{\circ} \mathrm{C}$ for $48 \mathrm{~h}$. Cell viability was evaluated by the MTT assay. Results were obtained from 3 independent experiments and were expressed as mean $\pm \mathrm{SD}\left({ }^{\#} \mathrm{P}<0.05,{ }^{\# \#} \mathrm{P}<0.01\right.$ versus the HG group; ${ }^{*} \mathrm{P}<0.05$ versus control). HG, high glucose; $\operatorname{Rg} 1$, ginsenoside $\operatorname{Rg} 1 ; \mathrm{SD}$, standard deviation.

Detection Kit (Solarbio, China), flow cytometry (Becton Dickinson, USA) was used to detect the apoptosis rate. Annexin V-FITC (-)/PI (-) (bottom left) were normal cells. Annexin V-FITC (+)/PI (-) cells (bottom right) were early apoptotic cells. Annexin V-FITC (+)/PI (+) (upper right) were late apoptotic cells. Annexin V (-)/PI (+) (upper left) were necrotic cells.

\section{Animal models and sample collection}

SPF male Sprague-Dawley rats (8 weeks, 180-200 g) were obtained from the Animal Center of Huazhong University of Science and Technology, which were reared at $24 \pm 1{ }^{\circ} \mathrm{C}$, $12 \mathrm{~h}$ light/dark cycle environment. All experiments were conducted in accordance with the National Institutes of Health Guidelines for The Care and Use of Laboratory Animals, and approved by the Animal Welfare Committee of Tongji Medical College, Huazhong University of Science and Technology (No. s0800910).

Diabetic rats were induced by intrabitoneal injection of $50 \mathrm{mg} / \mathrm{kg}$ streptozotocin (STZ). After 4 weeks of STZ injection, diabetic rats were randomly divided into 3 group $(n=8)$ : control group, DN group and $\mathrm{Rg} 1$ group. The control group was given distilled water, and the $\mathrm{Rg} 1$ group was given $50 \mathrm{mg} / \mathrm{kg} \mathrm{Rg} 1$ (32), intraperitoneal injection once a day, for 8 weeks. The rats were sacrificed, blood and kidney tissues were collected for further analysis.

\section{Histological examination}

Following the previous methods, kidney sections $(4-5 \mu \mathrm{m})$ were used to observe the renal injury with hematoxylineosin (HE) (33), Masson (34), and Pas (33) staining, and the images were captured using a light microscopy (Nikon, Japan).

\section{Western blotting}

Protein was extracted from cells using the Whole Protein Extraction Kit (Solarbio, China). Protein concentrations were detected by the BCA Protein Assay Kit (Solarbio, China). Proteins $(30 \mu \mathrm{g})$ were separated by $10 \%$ SDSPAGE and then transferred to PVDF membranes (Solarbio, China). After being blocked by $5 \%$ skim milk, the proteins were incubated overnight at $4{ }^{\circ} \mathrm{C}$ with the following primary antibodies: Bax (ab182733, 1:2,000, Abcam, UK), Bcl-2 (ab194583, 1:500-1:2,000, Abcam, UK), cleaved caspase-3 (\#9664, 1:1,000, Cell Signaling, USA), cleaved caspase-9 (\#9507, 1:1000, Cell Signaling, USA), PI3K (ab191606, 1:1,000, Abcam, UK), phospho-PI3K (PA5104853, 1:500-1:2,000, Thermo Fisher, USA), AKT (\#4691, 1:1,000, Cell Signaling, USA), phospho-AKT (\#9271, 1:1,000, Cell Signaling, USA), FOXO3 (\#2497, 1:1,000, Cell Signaling, USA), and GAPDH (ab9485, 1:2,500, Abcam, UK). The next day, the membrane was washed with PBS and incubated for $1 \mathrm{~h}$ with goat anti-rabbit IgG-HRP 
(Solarbio, China). These bands were observed by the ECL Chemiluminescence Detection Kit (Solarbio, China).

\section{Measurement of inflammatory factors and molecules related to oxidative stress}

The cells were centrifuged at $500 \times \mathrm{g}$ for $5 \mathrm{~min}$, and the supernatant was used for ELISA. The levels of TNF- $\alpha$, IL$1 \beta$, IL-6, malondialdehyde (MDA), lactate dehydrogenase $(\mathrm{LDH})$, superoxide dismutase (SOD), and glutathione peroxidase (GSH-Px) in HBZF-1 cells or rat serum were detected following the manufacturer's instructions of the ELISA kits (Beyotime, China).

\section{Measurement of intracellular oxidants and antioxidant enzyme activities}

Reactive oxygen species (ROS) production in HBZF-1 cells was detected by measuring 2,7-dihydrochlorofluorescein (DCF)-derived fluorescence through a flow cytometer. ROS was determined according to the instructions of the Reactive Oxygen Species Assay Kit (Beyotime, China).

\section{Statistical analysis}

Data are presented as the mean \pm standard deviation (SD), with experiments repeated at least 3 times. Statistical comparisons between different groups were conducted using one-way analysis of variance followed by Bonferroni's post hoc test using SPSS 22.0 (SPSS, Inc., Chicago, IL, USA). $\mathrm{P}<0.05$ was considered to indicate a statistically significant difference.

\section{Results}

Rg1 elevated the cell viability of HG-induced HBZY-1 cells

To explore the effect of Rg1 on HBZY-1 cells, cell viability was firstly measured. $\mathrm{Rg} 1$ increased the viability of HBZY1 cells in a dose-dependent manner at lower concentrations for $48 \mathrm{~h}$, while doses above $20 \mu \mathrm{mol} / \mathrm{L}$ were cytotoxic (Figure $1 B$ ). Therefore, $2.5,5$, and $10 \mu \mathrm{mol} / \mathrm{L} \mathrm{Rg} 1$ for $48 \mathrm{~h}$ was used for subsequent experiments. As shown in Figure 1C, $\mathrm{HG}$ treatment significantly suppressed cell viability compared with the control group. However, Rg1 treatment elevated cell viability compared with the HG group in a dose-dependent manner. These results indicated that $\operatorname{Rg} 1$ alleviated the suppressive effect of HG on the survival of HBZY-1 cells.

\section{Rg1 reduced HG-induced apoptosis of $H B Z Y-1$ cells}

We then explored the effect of $\operatorname{Rg} 1$ on cell apoptosis. As shown in Figure $2 A, 2 B$, the flow cytometry assay demonstrated that the cell apoptosis rate was strongly reduced after treatment with $\mathrm{Rg} 1$ in a dose-dependent manner. In addition, HG treatment decreased the protein level of Bcl-2, while that of Bax, cleaved caspase-3, and cleaved caspase-9 increased compared with the control group. However, Rg1 treatment reversed these effects (Figure 2C). These results indicated that $\mathrm{Rg} 1$ inhibited HGinduced apoptosis of HBZY-1 cells.

\section{Rg1 alleviated HG-induced inflammation}

To investigate the effect of Rg1 on HG-induced inflammatory responses, levels of inflammatory factors such as TNF- $\alpha$, IL$1 \beta$, and IL- 6 were measured by ELISA. Rg1 treatment dosedependently lowered high levels of TNF- $\alpha$, IL-1 $\beta$, and IL-6 induced by HG in HBZY-1 cells. These data demonstrated that $\mathrm{Rg} 1$ treatment attenuated the HG-induced inflammatory response in HBZY-1 cells (Figure 3A-3C).

\section{Rg1 alleviated HG-induced oxidative stress}

Oxidative stress is the major mechanism for radiationinduced cancer cell death. ROS production was measured with DCFH-DA. The levels of MDA, LDH, SOD, and GSH-Px were examined by ELISA. As shown in Figure $4 A-4 C, \operatorname{Rg} 1$ treatment dose-dependently decreased HGinduced ROS generation, MDA, and $\mathrm{LDH}$ accumulation in HG-induced HBZY-1 cells. In addition, Rg1 increased the activities of SOD and GSH-Px in a dose-dependent manner (Figure 4D,4E). The results demonstrated that $\operatorname{Rg} 1$ treatment alleviated HG-induced oxidative stress in HBZY-1 cells.

\section{Rg1 promoted the activation of the PI3K/AKT/FOXO3 patbway in vitro}

We further investigated the underlying molecular mechanisms of these findings. The activation of the PI3K/ AKT pathway was measured by western blot. As shown in Figure $5 A, 5 B$, the phosphorylation of PI3K (p-PI3K) and AKT (p-AKT) was reduced while the FOXO3 level was elevated in nuclei after induction by HG compared with 

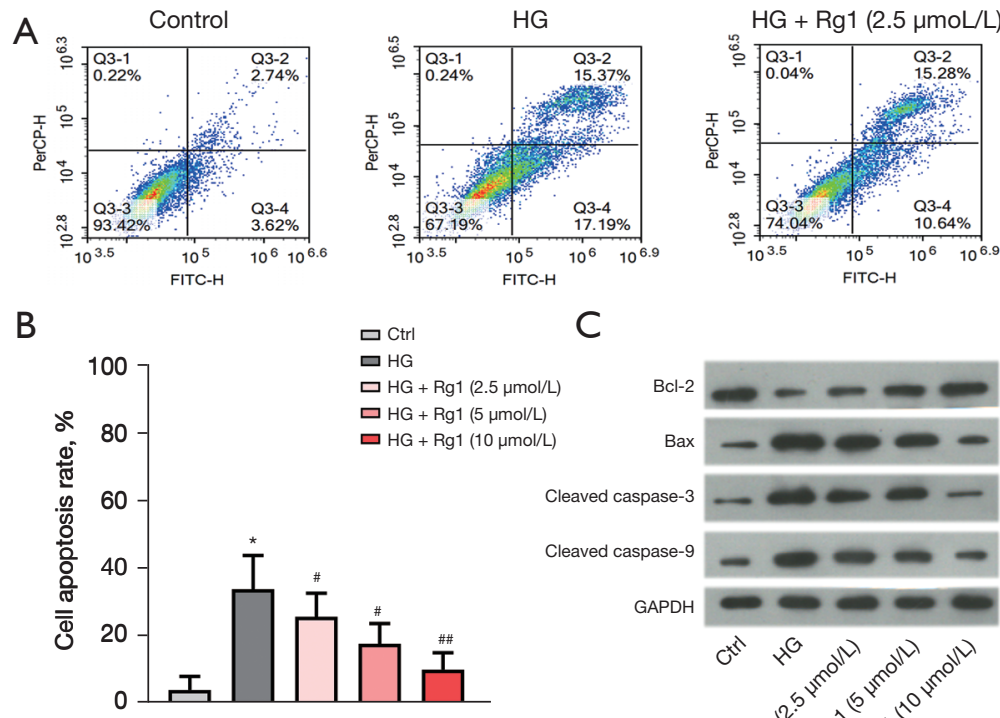

C
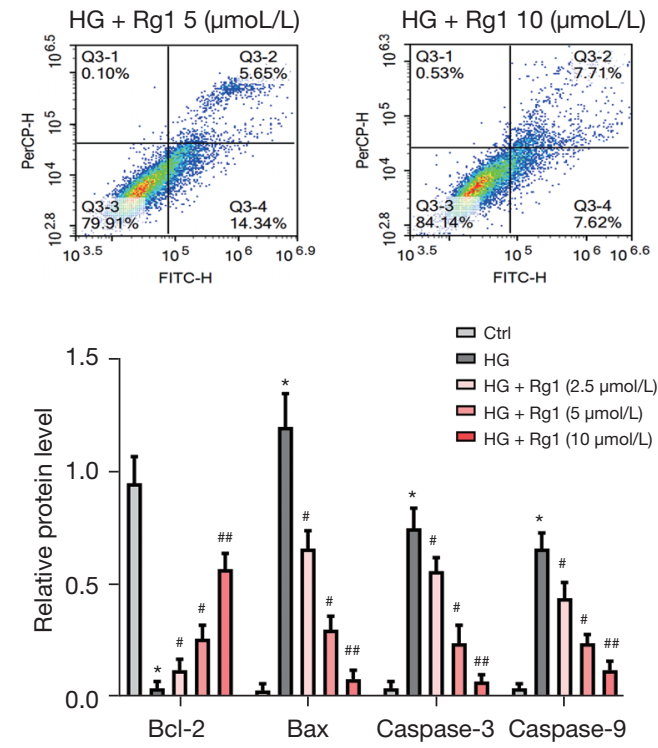

Figure $2 \mathrm{Rg} 1$ reduced HG-induced apoptosis of HBZY-1 cells. HBZY-1 cells were induced by HG (30 mmol/L). HBZY-1 cells were divided into 5 groups: control group (HBZY-1 cells without any treatment); HG group (HBZY-1 cells were induced by $30 \mathrm{mmol} / \mathrm{L}$ glucose); $\mathrm{HG}+\operatorname{Rg} 1(2.5,5,10 \mu \mathrm{mol} / \mathrm{L})$ group, where HG-induced HBZY-1 cells were treated with $2.5,5$, and $10 \mu \mathrm{mol} / \mathrm{L} \mathrm{Rg} 1$ at $37{ }^{\circ} \mathrm{C}$ for $48 \mathrm{~h}$. $(\mathrm{A}, \mathrm{B})$ The apoptosis rate of HBZY-1 cells was detected by the flow cytometry assay. (C) Levels of Bcl-2, Bax, cleaved caspase-3, and cleaved caspase- 9 were measured by western blot. ${ }^{*} \mathrm{P}<0.05$ versus control; ${ }^{\#} \mathrm{P}<0.05,{ }^{\# \#} \mathrm{P}<0.01$ versus the HG group. Rg1, ginsenoside Rg1; HG, high glucose.

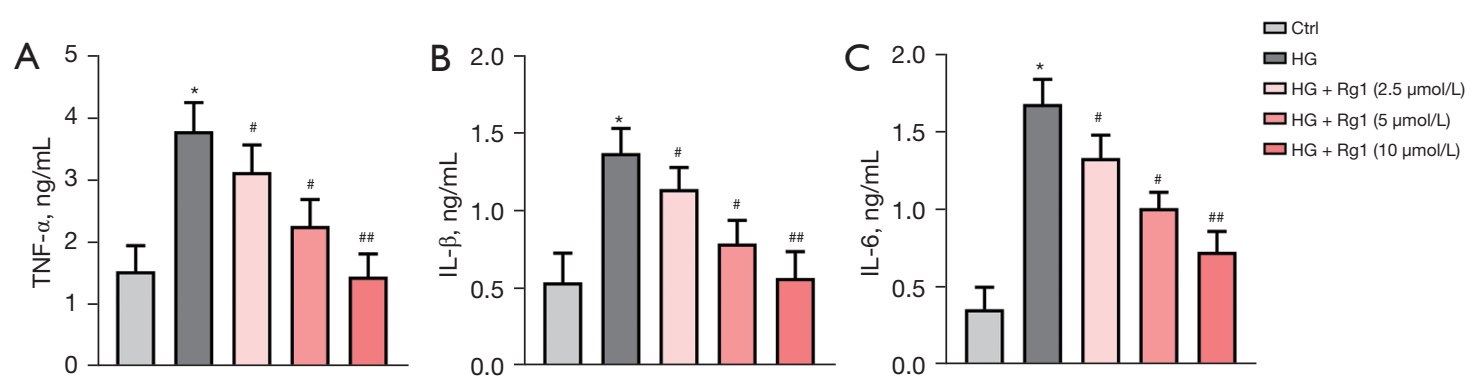

Figure $3 \mathrm{Rg} 1$ alleviated the HG-induced inflammatory response. HBZY-1 cells were induced by HG (30 mmol/L). HBZY-1 cells were divided into 5 groups: control group (HBZY-1 cells without any treatment); HG group (HBZY-1 cells were induced by 30 mmol/L glucose); HG + Rg1 (2.5, 5, $10 \mu \mathrm{mol} / \mathrm{L})$ group, where HG-induced HBZY-1 cells were treated with $2.5,5$, and $10 \mu \mathrm{mol} / \mathrm{L} \mathrm{Rg} 1$ at $37{ }^{\circ} \mathrm{C}$ for 48 h. (A) Level of TNF- $\alpha$ was determined by ELISA. (B) Level of IL-1 $\beta$ was determined by ELISA. (C) Level of IL-6 was determined by ELISA. ${ }^{*} \mathrm{P}<0.05$ versus control; ${ }^{\#} \mathrm{P}<0.05,{ }^{\#} \mathrm{P}<0.01$ versus the $\mathrm{HG}$ group. Rg1, ginsenoside Rg1; HG, high glucose; ELISA, enzyme-linked immunoassay.

the control group. However, $\operatorname{Rg} 1$ treatment increased the levels of $\mathrm{p}-\mathrm{PI} 3 \mathrm{~K}$ and $\mathrm{p}$-AKT and promoted the transfer of FOXO3 from the nucleus to the cytoplasm (Figure $5 A, 5 B$ ). These results indicated that $\mathrm{Rg} 1$ promoted the activation of the PI3K/AKT pathway to inactivate FOXO3.

\section{The PI3K/AKT/FOXO3 pathway was involved in the protective effect of $\mathrm{Rg} 1$ on $\mathrm{HG}$-induced $\mathrm{HBZY}-1$ cells}

To further confirm the involvement of the PI3K/AKT/ FOXO3 pathway, the AKT inhibitor, MK-2206, was added to HG-induced HBZY-1 cells. As shown in Figure $6 A, 6 B$, 
A

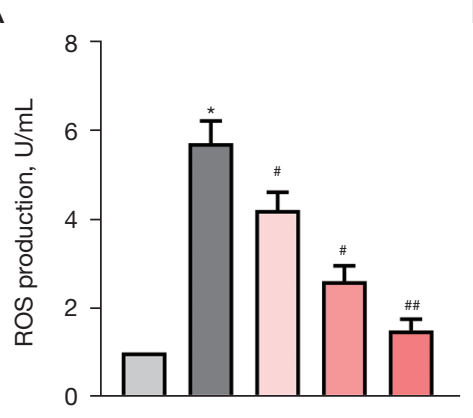

B
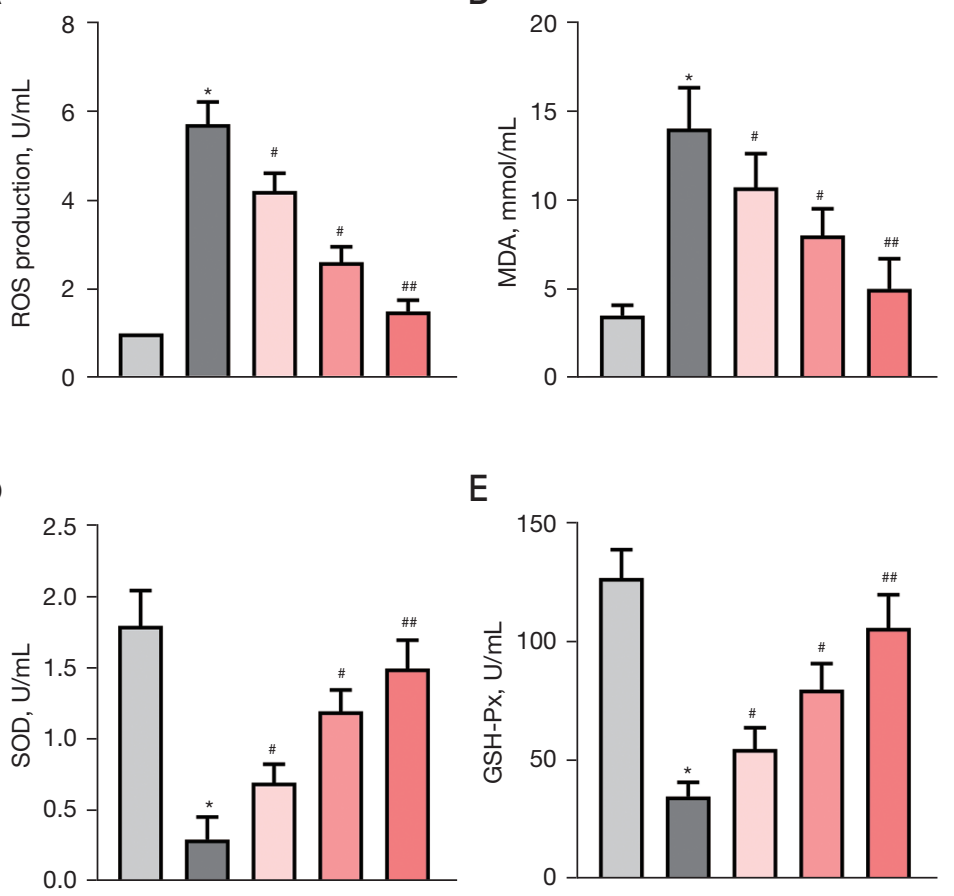

E

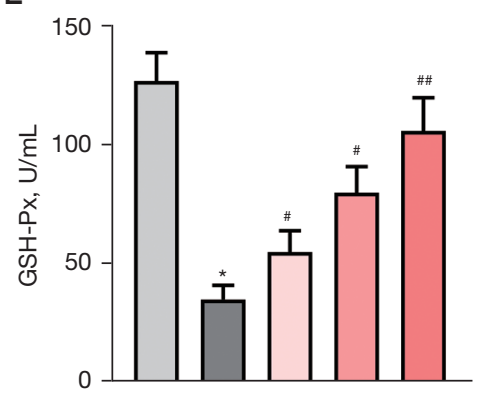

C

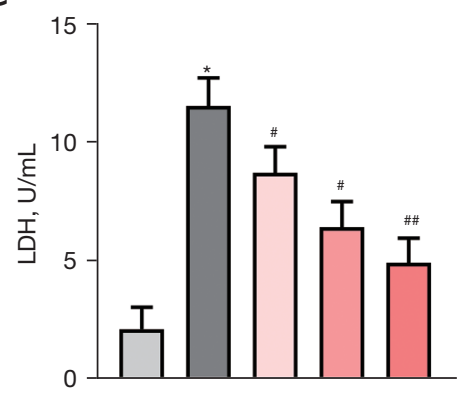

$\square$ Ctrl

口 $\mathrm{HG}$

口 $\mathrm{HG}+\mathrm{Rg} 1(2.5 \mu \mathrm{mol} / \mathrm{L})$

口 $\mathrm{HG}+\operatorname{Rg} 1(5 \mu \mathrm{mo} / \mathrm{L})$

口 $\mathrm{HG}+\operatorname{Rg} 1$ (10 $\mu \mathrm{mo} / \mathrm{L})$

Figure 4 Rg1 alleviated HG-induced oxidative stress. HBZY-1 cells were induced by HG ( $30 \mathrm{mmol} / \mathrm{L})$. HBZY-1 cells were divided into 5 groups: control group (HBZY-1 cells without any treatment); HG group (HBZY-1 cells were induced by $30 \mathrm{mmol} / \mathrm{L}$ glucose); HG + Rg1 (2.5, 5, $10 \mu \mathrm{mol} / \mathrm{L}$ ) group, where HG-induced HBZY-1 cells were treated with 2.5, 5, and $10 \mu \mathrm{mol} / \mathrm{L} \mathrm{Rg} 1$ at $37^{\circ} \mathrm{C}$ for $48 \mathrm{~h}$. (A) ROS production was determined by DCFH-DA. (B) MDA production was determined by ELISA. (C) LDH production was determined by ELISA. (D) SOD activity was determined by ELISA. (E) GSH-Px activity was determined by ELISA. ${ }^{*} \mathrm{P}<0.05$ versus control; ${ }^{*} \mathrm{P}<0.05,{ }^{\# \#} \mathrm{P}<0.01$ versus the HG group. Rg1, ginsenoside Rg1; HG, high glucose; ROS, reactive oxygen species; MDA, malondialdehyde; LDH, lactate dehydrogenase; SOD, superoxide dismutase; GSH-Px, glutathione peroxidase.
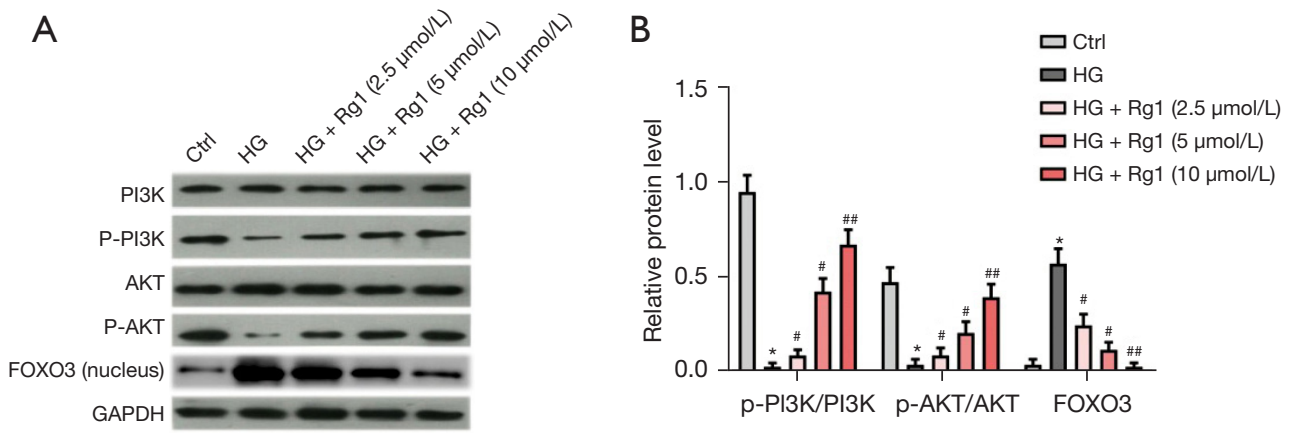

Figure 5 Rg1 promotes the activation of the PI3K/AKT/FOXO3 pathway in vitro. HBZY-1 cells were induced by HG (30 mmol/L). HBZY-1 cells were divided into 5 groups: control group (HBZY-1 cells without any treatment); HG group (HBZY-1 cells were induced by $30 \mathrm{mmol} / \mathrm{L}$ glucose); HG + Rg1 (2.5, 5, $10 \mu \mathrm{mol} / \mathrm{L})$ group, where HG-induced HBZY-1 cells were treated with 2.5, 5, and $10 \mu \mathrm{mol} / \mathrm{L} \mathrm{Rg} 1$ at $37^{\circ} \mathrm{C}$ for $48 \mathrm{~h}$. $(\mathrm{A}, \mathrm{B})$ Levels of $\mathrm{p}-\mathrm{PI} 3 \mathrm{~K} / \mathrm{PI} 3 \mathrm{~K}$, $\mathrm{p}-\mathrm{AKT} / \mathrm{AKT}$, and FOXO3 were measured by western blot. ${ }^{*} \mathrm{P}<0.05$ versus control; ${ }^{\#} \mathrm{P}<0.05,{ }^{{ }^{\prime \prime}} \mathrm{P}<0.01$ versus the HG group. Rg1, ginsenoside Rg1; HG, high glucose; p-PI3K, phosphorylation of PI3K; p-AKT, phosphorylation of AKT. 


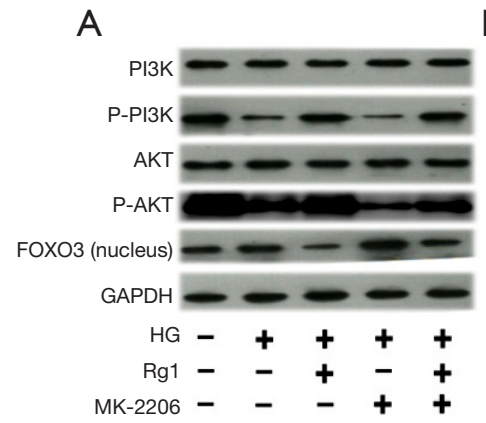

B

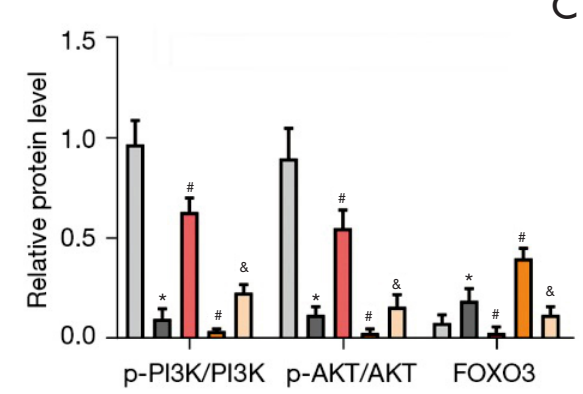

C

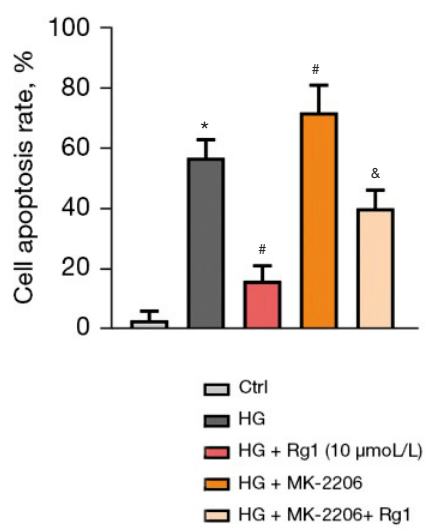

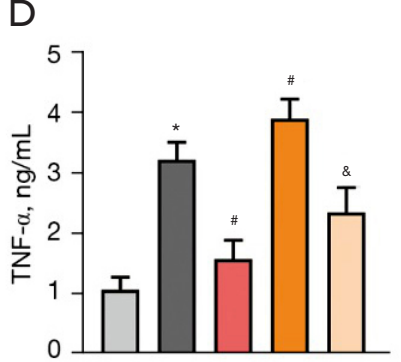

$\mathrm{E}$

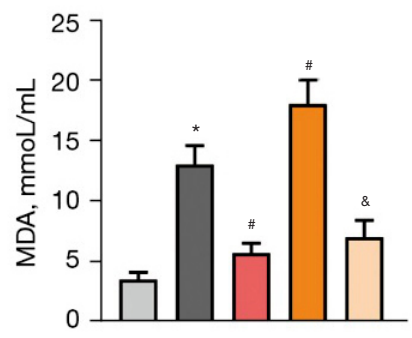

$\mathrm{F}$

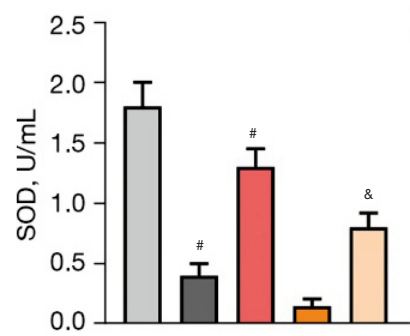

Figure 6 The PI3K/AKT/FOXO3 pathway was involved in the protective effect of Rg1 on HG-induced HBZY-1 cells. HBZY-1 cells were induced by HG (30 mmol/L). HBZY-1 cells were divided into 5 groups: control group (HBZY-1 cells without any treatment); HG group (HBZY-1 cells were induced by $30 \mathrm{mmol} / \mathrm{L}$ glucose); HG + Rg1 (10 $\mu \mathrm{mol} / \mathrm{L})$ group, where HG-induced HBZY-1 cells were treated with $10 \mu \mathrm{mol} / \mathrm{L} \mathrm{Rg} 1$ at $37^{\circ} \mathrm{C}$ for $48 \mathrm{~h}$; HG + MK-2206 (100 nmol/L) group, where HG-induced HBZY-1 cells were treated with $100 \mathrm{nmol} / \mathrm{L}$ MK-2206 at $37^{\circ} \mathrm{C}$ for $48 \mathrm{~h}$; HG + Rg1 + MK-2206 (100 nmol/L) group, where HG-induced HBZY-1 cells were treated with 10 mol/L $\mathrm{Rg} 1$ and $100 \mathrm{nmol} / \mathrm{L}$ MK-2206 at $37^{\circ} \mathrm{C}$ for $48 \mathrm{~h}$. (A,B) Levels of p-PI3K/PI3K, p-AKT/AKT, and FOXO3 were measured by western blot. (C) Apoptosis rate was measured by the flow cytometry assay. (D) TNF- $\alpha$ level was determined by ELISA. (E) MDA level was determined by ELISA. (F) SOD activity was determined by ELISA. ${ }^{*} \mathrm{P}<0.05$ versus control group; ${ }^{\#} \mathrm{P}<0.05$ versus the $\mathrm{HG}$ group; ${ }^{\circledR} \mathrm{P}<0.05$ versus the HG + MK-2206 (100 nmol/L) group. Rg1, ginsenoside Rg1; HG, high glucose; p-PI3K, phosphorylation of PI3K; p-AKT, phosphorylation of AKT; MDA, malondialdehyde; SOD, superoxide dismutase.

$\operatorname{Rg} 1(10 \mu \mathrm{mol} / \mathrm{mL})$ relieved the suppressive effect of HG on the PI3K/AKT pathway and reduced the FOXO3 level in the nucleus. However, the PI3K/AKT pathway was suppressed while the FOXO3 level was increased in the nucleus after the addition of MK-2206. Furthermore, the cell apoptosis rate and the levels of TNF- $\alpha$ and MDA were elevated while the activity of SOD was decreased with the addition of MK-2206. Rg1 treatment counteracted these effects (Figure 6C-6F). These results confirmed that the $\mathrm{PI} 3 \mathrm{~K} / \mathrm{AKT} / \mathrm{FOXO} 3$ pathway was involved in the protective effect of Rg1 on HG-induced HBZY-1 cells.

\section{Rg1 protects against $D N$ in vivo}

As shown in Figure 7A. Compared with control group, DN group showed symptoms of glomerular atrophy, severe proliferation of glomerular thylakoid, renal tubule dermal separation, basement membrane exposure, inflammatory cell cytoplasmic infiltration and interstitial edema. The above symptoms disappeared after $\mathrm{Rg} 1$ treatment. These results indicated that $\mathrm{Rg}$ can alleviate renal injury in $\mathrm{DN}$ mice. In addition, $\operatorname{Rg} 1$ treatment lowered high levels of TNF- $\alpha$ (Figure 7B) and IL-6 (Figure 7C) in STZ-induced rats. Rg1 treatment decreased STZ-induced MDA accumulation (Figure 7D), increased the activities of SOD (Figure 7E). Furthermore, $\mathrm{Rg} 1$ treatment increased the levels of p-PI3K and $\mathrm{p}-\mathrm{AKT}$ and promoted the transfer of $\mathrm{FOXO} 3$ from the nucleus to the cytoplasm (Figure $7 F$ ).

\section{Discussion}

As one of the most common complications of diabetes, $\mathrm{DN}$ has been the main cause of death in diabetic patients. GMCs are crucial cells which provide structural support 
A

HE
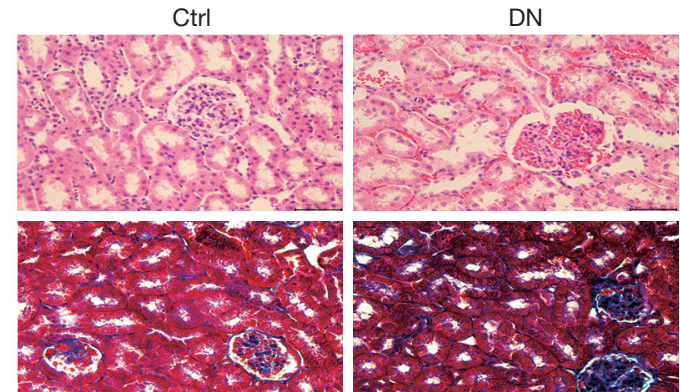

MASSON

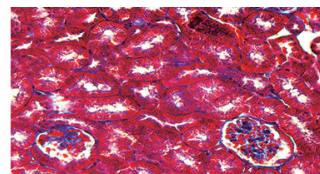

PAS
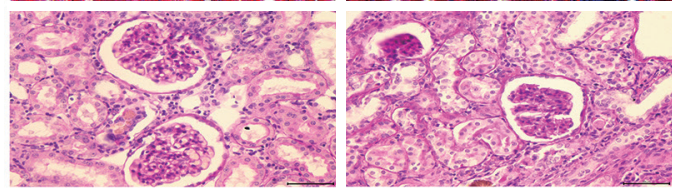

$\mathrm{DN}+\mathrm{Rg} 1(5 \mathrm{mg} / \mathrm{kg})$

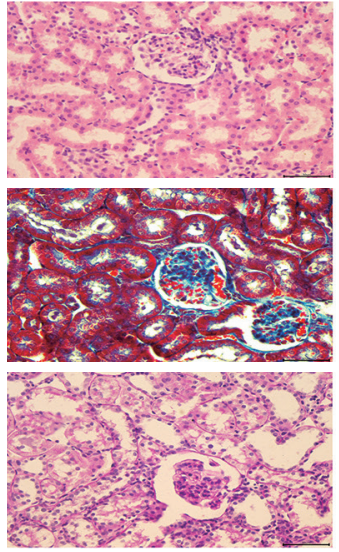

B

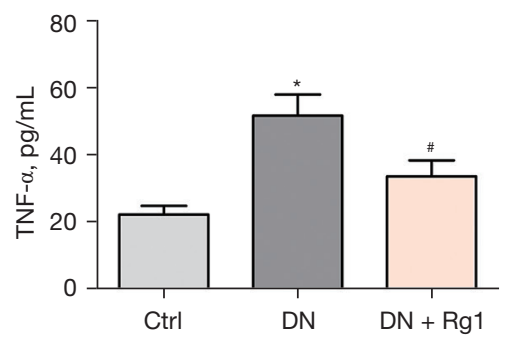

D

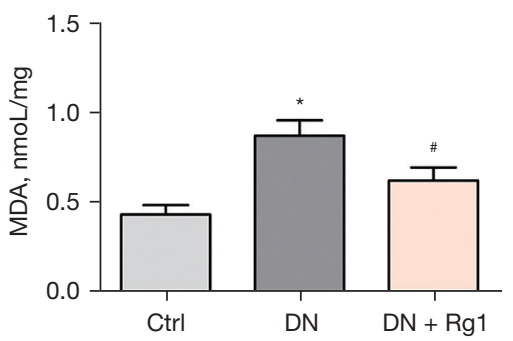

$\mathrm{F}$

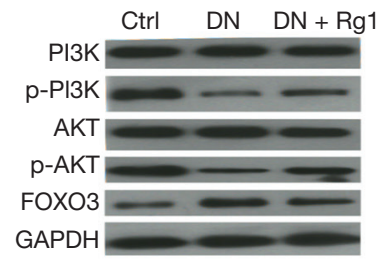

C

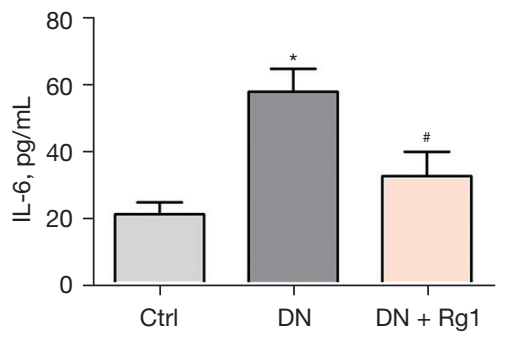

$\mathrm{E}$
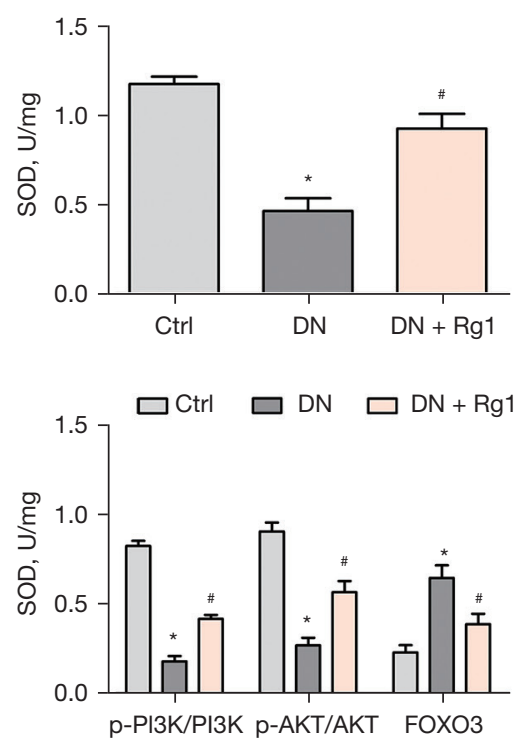

Figure 7 The effect of $\mathrm{Rg} 1$ in $\mathrm{DN}$ rat. (A) Diabetic rats were randomly divided into 3 group ( $\mathrm{n}=8$ ): control group, DN group and $\mathrm{Rg} 1$ group. Representative photograph for HE, Masson, PAS staining, scale bar $=25 \mu \mathrm{m}$. (B) Level of TNF- $\alpha$ was determined by ELISA. (C) Level of IL-6 was determined by ELISA. (D) MDA production was determined by ELISA. (E) SOD activity was determined by ELISA. (F) Levels of p-PI3K/PI3K, p-AKT/AKT, and FOXO3 were measured by western blot. ${ }^{*} \mathrm{P}<0.05$ versus control group; ${ }^{*} \mathrm{P}<0.05$ versus the DN group. Rg1, ginsenoside Rg1; DN, diabetic nephropathy; HE, hematoxylin-eosin; p-PI3K, phosphorylation of PI3K; p-AKT, phosphorylation of AKT; MDA, malondialdehyde; SOD, superoxide dismutase; ELISA, enzyme-linked immunoassay. 
for capillary loops and regulate glomerular filtration in the glomerulus (35). Research has indicated that GMC apoptosis participates in the pathogenesis of glomerulosclerosis and renal tubular interstitial fibrosis, leading to DN (36). Inflammation also plays vital roles in the pathogenesis of $\mathrm{DN}$ (37).

HG-induced oxidative stress plays an important role in cell growth. HG induced ROS production, increased MDA levels, and inhibited the SOD activity of GMCs $(6,38,39)$. Furthermore, in Zhang et al.'s research, HGinduced oxidative stress increased neuronal ROS, promoted apoptosis, and decreased cell viability (40). Similarity, in our study, we found that under the stimulation of HG, the viability of HBZY-1 cells was markedly inhibited compared to controls. We also found that exposure to HG induced a significant increase in the levels of TNF- $\alpha$, IL- $1 \beta$, IL6, MDA, LDH, and ROS while inhibiting the activities of SOD and GSH-Px. Furthermore, GMC apoptosis was also observed under HG conditions. Collectively, our results showed that HG-induced inflammation and oxidative stress accelerated GMC apoptosis. In vivo studies showed that injection of $\operatorname{Rg} 1(50 \mathrm{mg} / \mathrm{kg} / \mathrm{d})$ in rats improved glomerular atrophy, severe proliferation of glomerular thylakoids, detachment of renal tubular endothelium, exposure of basement membrane, inflammatory cell cytoplasmic infiltration and interstitial edema (41), indicating the therapeutic potential of $\operatorname{Rg} 1$ in DN. Previous studies have shown that $\mathrm{Rg} 1$ combined with astragaloside IV can protect renal function, which may be related to antioxidant stress (42). In this study, we confirmed the protective effect of $\mathrm{Rg} 1$ in DN rats, and further studied the effect of $\mathrm{Rg} 1$ on inflammation and oxidative stress in vitro and in vivo.

Traditional Chinese medicine has been used for thousands of years, which isolates have many pharmacological activities (43). The anti-diabetic effects of different extracts on animal models have been reported $(44,45)$. As one of the primary bioactive ingredients in Panax notoginseng saponins, $\operatorname{Rg} 1$ has demonstrated multiple beneficial effects, including anti-inflammation (12) and neuroprotection (10). Accumulating evidence suggests that $\operatorname{Rg} 1$ has remarkable antioxidant properties. $\mathrm{Li}$ and Ning et al. showed that treatment with $\mathrm{Rg} 1$ markedly suppressed apoptosis and caspase- 3 activation, and reduced ROS and MDA production by enhancing the antioxidant capacity of SOD and GSH-Px $(46,47)$. Furthermore, $\mathrm{Rg} 1$ significantly increased cell viability and protected HK-2 cells from LPS-induced injury in a dose-dependent manner (12). Additionally, $\operatorname{Rg} 1$ could induce apoptosis through regulating the expression of apoptotic proteins (46). Consistent with these results, we found that $\mathrm{Rg} 1$ promoted cell viability and alleviated cell apoptosis and oxidative stress induced by HG in a dose-dependent manner.

As an important downstream target of PI3K/AKT, FOXO3 is mainly regulated by the PI3K/AKT signaling pathway $(25,26)$. Song et al. reported that GSH strengthened the survival of brain endothelial cells by activating the PI3K/Akt pathway and suppressing the translocation of FOXO3 into the nucleus (48). In addition, further study showed that $\operatorname{Rg} 1$ inhibited apoptosis by triggering PI3K/ AKT activation and FOXO3 phosphorylation (49). Our study indicated that $\mathrm{Rg} 1$ elevated the levels of p-PI3K and $\mathrm{p}$-AKT and reduced the FOXO3 level in the nucleus in a dose-dependent manner. This alteration varied with the addition of MK-2206. These results confirmed that the $\mathrm{PI} 3 \mathrm{~K} / \mathrm{AKT} / \mathrm{FOXO} 3$ pathway was involved in the protective effect of Rg1 on HG-induced HBZY-1 cells. Consistent with this, our findings in DN rat model also support this view.

In conclusion, $\operatorname{Rg} 1$ elevated the survival rates and reduced the apoptosis induced by HG in HBZY-1 cells. Rg1 alleviated $\mathrm{DN}$-induced inflammation and oxidative stress by promoting the $\mathrm{PI} 3 \mathrm{~K} / \mathrm{AKT} / \mathrm{FOXO} 3$ pathway. Rg1 may therefore be a new drug target against $\mathrm{DN}$.

\section{Acknowledgments}

Funding: This work was supported by the Wuhan Municipal Health Commission Medical Research Project Fund (WX20D51).

\section{Footnote}

Reporting Checklist: The authors have completed the MDAR reporting checklist. Available at https://dx.doi. org/10.21037/atm-21-6234

Data Sharing Statement: Available at https://dx.doi. org/10.21037/atm-21-6234

Conflicts of Interest: All authors have completed the ICMJE uniform disclosure form (available at https://dx.doi. org/10.21037/atm-21-6234). The authors have no conflicts of interest to declare.

Ethical Statement: The authors are accountable for all aspects of the work in ensuring that questions related 
to the accuracy or integrity of any part of the work are appropriately investigated and resolved. All experiments were conducted in accordance with the National Institutes of Health Guidelines for The Care and Use of Laboratory Animals, and approved by the Animal Welfare Committee of Tongji Medical College, Huazhong University of Science and Technology (No. s0800910).

Open Access Statement: This is an Open Access article distributed in accordance with the Creative Commons Attribution-NonCommercial-NoDerivs 4.0 International License (CC BY-NC-ND 4.0), which permits the noncommercial replication and distribution of the article with the strict proviso that no changes or edits are made and the original work is properly cited (including links to both the formal publication through the relevant DOI and the license). See: https://creativecommons.org/licenses/by-nc-nd/4.0/.

\section{References}

1. Dronavalli S, Duka I, Bakris GL. The pathogenesis of diabetic nephropathy. Nat Clin Pract Endocrinol Metab 2008;4:444-52.

2. Mishra R, Emancipator SN, Kern T, et al. High glucose evokes an intrinsic proapoptotic signaling pathway in mesangial cells. Kidney Int 2005;67:82-93.

3. Ortiz-Muñoz G, Lopez-Parra V, Lopez-Franco O, et al. Suppressors of cytokine signaling abrogate diabetic nephropathy. J Am Soc Nephrol 2010;21:763-72.

4. Tziomalos K, Athyros VG. Diabetic Nephropathy: New Risk Factors and Improvements in Diagnosis. Rev Diabet Stud 2015;12:110-8.

5. Ni WJ, Ding HH, Tang LQ. Berberine as a promising anti-diabetic nephropathy drug: An analysis of its effects and mechanisms. Eur J Pharmacol 2015;760:103-12.

6. Sun Z, Ma Y, Chen F, et al. Artesunate ameliorates high glucose-induced rat glomerular mesangial cell injury by suppressing the TLR4/NF-кB/NLRP3 inflammasome pathway. Chem Biol Interact 2018;293:11-9.

7. Ying C, Chen L, Wang S, et al. Zeaxanthin ameliorates high glucose-induced mesangial cell apoptosis through inhibiting oxidative stress via activating AKT signallingpathway. Biomed Pharmacother 2017;90:796-805.

8. Arellano-Buendía AS, García-Arroyo FE, Cristóbal-García $\mathrm{M}$, et al. Urinary excretion of neutrophil gelatinaseassociated lipocalin in diabetic rats. Oxid Med Cell Longev 2014;2014:961326.

9. Li J, Wei Q, Zuo GW, et al. Ginsenoside Rg1 induces apoptosis through inhibition of the EpoR-mediated JAK2/ STAT5 signalling pathway in the TF-1/ Epo human leukemia cell line. Asian Pac J Cancer Prev 2014;15:2453-9.

10. Chu SF, Zhang Z, Zhou X, et al. Ginsenoside Rg1 protects against ischemic/reperfusion-induced neuronal injury through miR-144/Nrf2/ARE pathway. Acta Pharmacol Sin 2019;40:13-25.

11. Zeng $\mathrm{Y}, \mathrm{Hu} \mathrm{W}$, Jing $\mathrm{P}$, et al. The regulation of ginsenoside Rg1 upon aging of bone marrow stromal cell contribute to delaying senescence of bone marrow mononuclear cells (BMNCs). Life Sci 2018;209:63-8.

12. Ni XJ, Xu ZQ, Jin H, et al. Ginsenoside Rg1 protects human renal tubular epithelial cells from lipopolysaccharide-induced apoptosis and inflammation damage. Braz J Med Biol Res 2017;51:e6611.

13. Wang ZL, Chen LB, Qiu Z, et al. Ginsenoside Rg1 ameliorates testicular senescence changes in D-gal-induced aging mice via anti-inflammatory and antioxidative mechanisms. Mol Med Rep 2018;17:6269-76.

14. Lee $\mathrm{CH}, \mathrm{Kim} \mathrm{JH}$. A review on the medicinal potentials of ginseng and ginsenosides on cardiovascular diseases. J Ginseng Res 2014;38:161-6.

15. Nie L, Xia J, Li H, et al. Ginsenoside Rg1 Ameliorates Behavioral Abnormalities and Modulates the Hippocampal Proteomic Change in Triple Transgenic Mice of Alzheimer's Disease. Oxid Med Cell Longev 2017;2017:6473506.

16. Tang YY, Guo WX, Lu ZF, et al. Ginsenoside Rg1 Promotes the Migration of Olfactory Ensheathing Cells via the PI3K/Akt Pathway to Repair Rat Spinal Cord Injury. Biol Pharm Bull 2017;40:1630-7.

17. Ning C, Gao X, Wang C, et al. Ginsenoside Rg1 protects against acetaminophen-induced liver injury via activating Nrf2 signaling pathway in vivo and in vitro. Regul Toxicol Pharmacol 2018;98:58-68.

18. Xu Y, Yang C, Zhang S, et al. Ginsenoside Rg1 Protects against Non-alcoholic Fatty Liver Disease by Ameliorating Lipid Peroxidation, Endoplasmic Reticulum Stress, and Inflammasome Activation. Biol Pharm Bull 2018;41:1638-44.

19. Xue LP, Fu XL, Hu M, et al. Rg1 inhibits high glucoseinduced mesenchymal activation and fibrosis via regulating miR-2113/RP11-982M15.8/Zeb1 pathway. Biochem Biophys Res Commun 2018;501:827-32.

20. Yu HT, Zhen J, Pang B, et al. Ginsenoside Rg1 ameliorates oxidative stress and myocardial apoptosis in streptozotocin-induced diabetic rats. J Zhejiang Univ Sci B 2015;16:344-54. 
21. Sanchez AM, Candau RB, Bernardi H. FoxO transcription factors: their roles in the maintenance of skeletal muscle homeostasis. Cell Mol Life Sci 2014;71:1657-71.

22. Beard RS Jr, Haines RJ, Wu KY, et al. Non-muscle Mlck is required for $\beta$-catenin- and FoxO1-dependent downregulation of Cldn 5 in IL-1 $\beta$-mediated barrier dysfunction in brain endothelial cells. J Cell Sci 2014;127:1840-53.

23. Fukunaga K, Shioda N. Pathophysiological relevance of forkhead transcription factors in brain ischemia. Adv Exp Med Biol 2009;665:130-42.

24. Zhou W, Cao Q, Peng Y, et al. FoxO4 inhibits NF-kappaB and protects mice against colonic injury and inflammation. Gastroenterology 2009;137:1403-14.

25. Brunet A, Bonni A, Zigmond MJ, et al. Akt promotes cell survival by phosphorylating and inhibiting a Forkhead transcription factor. Cell 1999;96:857-68.

26. Skurk C, Izumiya Y, Maatz H, et al. The FOXO3a transcription factor regulates cardiac myocyte size downstream of AKT signaling. J Biol Chem 2005;280:20814-23.

27. Storz P. Forkhead homeobox type O transcription factors in the responses to oxidative stress. Antioxid Redox Signal 2011;14:593-605.

28. Carbajo-Pescador S, Mauriz JL, García-Palomo A, et al. FoxO proteins: regulation and molecular targets in liver cancer. Curr Med Chem 2014;21:1231-46.

29. Chung HW, Lim JH, Kim MY, et al. High-fat dietinduced renal cell apoptosis and oxidative stress in spontaneously hypertensive rat are ameliorated by fenofibrate through the PPAR $\alpha$-FoxO3a-PGC- $1 \alpha$ pathway. Nephrol Dial Transplant 2012;27:2213-25.

30. Holm K, Isacson O. Factors intrinsic to the neuron can induce and maintain its ability to promote axonal outgrowth: a role for BCL2? Trends Neurosci 1999;22:269-73.

31. Reed JC, Doctor KS, Godzik A. The domains of apoptosis: a genomics perspective. Sci STKE 2004;2004:re9.

32. Shi Y, Gao Y, Wang T, et al. Ginsenoside Rg1 Alleviates Podocyte EMT Passage by Regulating AKT/GSK3 $\beta$ / $\beta$-Catenin Pathway by Restoring Autophagic Activity. Evid Based Complement Alternat Med 2020;2020:1903627.

33. Xie XS, Liu HC, Wang FP, et al. Ginsenoside Rg1 modulation on thrombospondin-1 and vascular endothelial growth factor expression in early renal fibrogenesis in unilateral obstruction. Phytother Res 2010;24:1581-7.

34. Feng Y, Weng H, Ling L, et al. Modulating the gut microbiota and inflammation is involved in the effect of
Bupleurum polysaccharides against diabetic nephropathy in mice. Int J Biol Macromol 2019;132:1001-11.

35. Najafian B, Alpers CE, Fogo AB. Pathology of human diabetic nephropathy. Contrib Nephrol 2011;170:36-47.

36. Chen YQ, Wang XX, Yao XM, et al. Abated microRNA-195 expression protected mesangial cells from apoptosis in early diabetic renal injury in mice. J Nephrol 2012;25:566-76.

37. Liu Z, Han Y, Zhao F, et al. Nobiletin suppresses highglucose-induced inflammation and ECM accumulation in human mesangial cells through STAT3/NF- $\kappa$ B pathway. J Cell Biochem 2019;120:3467-73.

38. Chen F, Ma Y, Sun Z, et al. Tangeretin inhibits high glucose-induced extracellular matrix accumulation in human glomerular mesangial cells. Biomed Pharmacother 2018;102:1077-83.

39. Wang S, Zhao X, Yang S, et al. Salidroside alleviates high glucose-induced oxidative stress and extracellular matrix accumulation in rat glomerular mesangial cells by the TXNIP-NLRP3 inflammasome pathway. Chem Biol Interact 2017;278:48-53.

40. Zhang YP, Liu SY, Sun QY, et al. Proanthocyanidin B2 attenuates high-glucose-induced neurotoxicity of dorsal root ganglion neurons through the PI3K/Akt signaling pathway. Neural Regen Res 2018;13:1628-36.

41. Gao Z, Kong D, Cai W, et al. Characterization and anti-diabetic nephropathic ability of mycelium polysaccharides from Coprinus comatus. Carbohydr Polym 2021;251:117081.

42. Du N, Xu Z, Gao M, et al. Combination of Ginsenoside Rg1 and Astragaloside IV reduces oxidative stress and inhibits TGF- $\beta 1 /$ Smads signaling cascade on renal fibrosis in rats with diabetic nephropathy. Drug Des Devel Ther 2018;12:3517-24.

43. Liu W, Wu Y, Hu Y, et al. Effects of Cyclocarya paliurus Aqueous and Ethanol Extracts on Glucolipid Metabolism and the Underlying Mechanisms: A Meta-Analysis and Systematic Review. Front Nutr 2020;7:605605.

44. Liu Y, Cao Y, Fang S, et al. Antidiabetic Effect of Cyclocarya paliurus Leaves Depends on the Contents of Antihyperglycemic Flavonoids and Antihyperlipidemic Triterpenoids. Molecules 2018;23:1042.

45. Seo E, Kang H, Oh YS, et al. Psoralea corylifolia L. Seed Extract Attenuates Diabetic Nephropathy by Inhibiting Renal Fibrosis and Apoptosis in Streptozotocin-Induced Diabetic Mice. Nutrients 2017;9:828.

46. Li Q, Xiang Y, Chen Y, et al. Ginsenoside Rg1 Protects Cardiomyocytes Against Hypoxia/Reoxygenation Injury 
via Activation of Nrf2/HO-1 Signaling and Inhibition of JNK. Cell Physiol Biochem 2017;44:21-37.

47. Ning C, Gao X, Wang C, et al. Hepatoprotective effect of ginsenoside $\mathrm{Rg} 1$ from Panax ginseng on carbon tetrachloride-induced acute liver injury by activating Nrf2 signaling pathway in mice. Environ Toxicol 2018;33:1050-60.

48. Song J, Park J, Oh Y, et al. Glutathione suppresses cerebral infarct volume and cell death after ischemic

Cite this article as: Liu $\mathrm{H}$, Chen $\mathrm{W}$, Lu P, Ma Y, Liang X, Liu Y. Ginsenoside $\operatorname{Rg} 1$ attenuates the inflammation and oxidative stress induced by diabetic nephropathy through regulating the PI3K/AKT/FOXO3 pathway. Ann Transl Med 2021;9(24):1789. doi: 10.21037/atm-21-6234 injury: involvement of FOXO3 inactivation and $\mathrm{Bcl} 2$ expression. Oxid Med Cell Longev 2015;2015:426069.

49. Liu Y, Yi L, Wang L, et al. Ginsenoside Rg1 protects human umbilical cord blood-derived stromal cells against tert-Butyl hydroperoxide-induced apoptosis through Akt-FoxO3a-Bim signaling pathway. Mol Cell Biochem 2016;421:75-87.

(English Language Editor: C. Betlazar-Maseh) 